\title{
Physiological Signatures of Dual Embryonic Origins in Mouse Skull Vault
}

\author{
Bo Hua Taofen Wu ${ }^{b}$ Yongxu Zhao ${ }^{c}$ Guangtao $\mathrm{Xu}^{\mathrm{a}}$ Ruilin Shen \\ Guiqian Chen ${ }^{\mathrm{a}, \mathrm{d}}$
}

aDepartment of Pathology and Diabetes Institute, Jiaxing Hospital of Traditional Chinese Medicine, Jiaxing University, Jiaxing, ${ }^{b}$ College of Animal Science, Zhejiang University, Hangzhou, ${ }^{c}$ Veterinary Medicine, Nanjing Agricultural University, Nanjing, China; ${ }^{\mathrm{d}}$ Regenerative Bioscience Center, University of Georgia, Athens, USA

\section{Key Words}

Neural crest cells $\bullet$ Mesoderm $\cdot$ Skull $•$ Frontal bone $\cdot$ Parietal bone

\begin{abstract}
Background/Aims: The mammalian skull vault is a highly regulated structure and consists of several membrane bones of different tissue origins (e.g. neural crest derived frontal bone and mesoderm derived parietal bone). Although membrane bones form through intramembranous ossification, neural crest derived frontal bone has superior osteoblast activity and bone regeneration ability, triggering a novel conception for craniofacial reconstruction and bone regeneration called endogenous calvarial regeneration. However, a comprehensive landscape of the genes and signaling pathways involved in this process is not clear. Methods: Transcriptome analysis within the two bone elements is firstly performed to determine the physiological signatures of differential gene expressions in mouse skull vault. Results: Frontal bone tissues and parietal bone tissues maintain tissue origin through special gene expression similar to neural crest vs mesoderm tissue, and physiological functions between these two tissues are also found in differences related to proliferation, differentiation and extracellular matrix production and clustered signaling pathways. Conclusion: Our data provide novel insights into the potential gene regulatory network in regulating the development of neural crest-derived frontal bone and mesoderm-derived parietal bone.
\end{abstract}

\section{Introduction}

(C) 2017 The Author(s)

Published by S. Karger AG, Basel

The mammalian skull vault is a highly regulated and exquisitely patterned structure. It consists of several membrane bones of different tissue origin, namely a pair of frontal bones and parietal bones and unpaired inter-parietal bone. Frontal bones are cranial neural crest (CNC) derived tissue, and parietal bones are of paraxial mesoderm origin [1, 2]. Both frontal bone and parietal bone utilize the same mechanism for bone formation. Interestedly, the osteoblast activities from these two tissue origins show different characteristics: neural 
crest-derived osteoblasts are showing to be less differentiated, faster growing, with fast bone nodule formation compared to parietal bone-derived osteoblasts [3]. In addition, FGF ligands and receptors highly expressed in frontal bone [4], suggesting their roles in mediating biological differences within the two types of bones [4]. Canonical Wnt signaling also contributes to the superior osteogenic potential and tissue regeneration in neural crestderived frontal bone [5]. Enhanced activation of Wnt signaling is capable to transform the physiological behavior of parietal bone into a degree similar to neural crest derived frontal bone [6]. Besides, frontal bone tissues show low apoptosis when stimulated by TGF signaling [7]. Due to superior activities of osteoblasts and bone regeneration within frontal bone, a novel thought for craniofacial construction--endogenous calvarial regeneration has been proposed. However, except the findings from TGF, Wnt and FGF signaling pathway, the cellular and genetic differences to regulate neural crest derived frontal bone and mesoderm derived parietal bone remain largely unknown.

In order to understand the physiological signatures or differences of embryonic tissue origins in skull vault, transcriptome sequencing from the two bone elements were performed. Our data provide novel insights into the potential gene regulatory network that may guide the genetic and molecular differences within the two bone tissues, which provide a basis to identify molecular target that can switch endogenous regeneration to heal the damaged bone.

\section{Materials and Methods}

\section{Animals}

All the animal experiments were performed in compliance with Jiaxing University Animal Care and Use Committee guidelines. C57BL/6 female mice (Mus musculus) were ordered from Hangzhou Normal University Animal Use Center. Animals were housed in light-and temperature-controlled rooms and were given food and water ad libitum.

\section{Tissue Harvest}

Three pregnant mice at embryonic stage of E17.5 were used to harvest frontal bones (Fb) and parietal bones $(\mathrm{Pb})$ based on published methods [8]. Each tissue was collected from 6 independent littermates. The tissues were immediately placed in dry ice and labeled for total RNA extraction. Bone tissues were mechanically homogenized in $1 \mathrm{ml}$ Trizol reagent. RNA extraction were performed using Trizol and the procedures were performed based on the kit guidelines. The qualities of total RNA were measured using Bioanalyzer 2100 and RNA 6000 Nano LabChip Kit (Agilent, CA, USA), and samples with only O.D. 260/280 $>1.8$, and O.D. 260/230> 1.5 and RNA integrity number greater than 8 were used for the transcriptome analysis.

\section{cDNA library generation and sequencing}

Total 10 ug RNA was used to isolate and purify the Poly (A) mRNA with poly-T oligo attached magnetic beads (Invitrogen). Following purification, the mRNAs were fragmented into small pieces using divalent cations under elevated temperature. The cleaved RNA fragments were reverse-transcribed to generate initial cDNA library, which was further purified and prepared for the sequenced cDNA library according to the protocol for the mRNA-Seq Sample Preparation Kit (Illumina, San Diego, USA). The average insert size for the paired-end libraries was about $300 \mathrm{bp}( \pm 50 \mathrm{bp}$ ). The paired-end sequencing was performed using an Illumina Hiseq2000/2500.

\section{Alignments and annotations}

RNA-seq yielded about 8.18-8.76 gigabases $(\mathrm{Gb})$ of sequenced reads in different treated samples. Prior to assembly, reads with low quality were removed and the qualities of reads were further checked using Fast-QC v0.11.4. The qualities of sequenced reads in six samples were shown (for all online suppl. material, see www.karger.com/doi/10.1159/000484496) in Suppl. Table S1. We aligned $\mathrm{Fb}$ and $\mathrm{Pb}(\mathrm{n}=3)$ reads to the UCSC (http://genome.ucsc.edu/) Mus musculus reference genome using Tophat package with default 


\section{Cellular Physiology Cell Physiol Biochem 2017;43:2525-2534 \begin{tabular}{l|l|l} 
and Biochemistry $\begin{array}{l}\text { DOI: 10.1159/000484496 } \\
\text { Published online: November 02, } 2017\end{array}$ & $\begin{array}{l}\text { (c) } 2017 \text { The Author(s). Published by S. Karger AG, Basel } \\
\text { www.karger.com/cpb }\end{array}$
\end{tabular}}

Hu et al.: Dual Tissue Origins Within Skull Vault

parameters. Paired-end clean reads about 8.04-8.59 G bp were produced in treated groups. The detailed alignment information was shown (see online suppl. material) in Suppl. Table S2, including the numbers of reads, mapped reads, and unique mapped reads.

\section{Identification of differentially expressed genes (DEGs)}

The aligned read files were analyzed by Cufflinks $[9,10]$, which used the normalized RNA-seq fragment counts to measure the relative abundances of the transcripts. The unit of measurement was called Fragment Per Kilobase of exon per Million fragments mapped (FPKM). The reference GTF annotation file used in Cufflinks was from the UCSC database. Cufflink was used to de novo assemble the transcriptome first. Next, Cuff-merge was used to co-merge all transcripts of sample to generate unique transcripts. The downloaded UCSC GTF file was passed to Cuffdiff along with the original alignment (SAM) files produced by Tophat. Cuffdiff re-estimated the abundance of the transcripts listed in the GTF file using alignments from the SAM file and concurrently tested for different expression. Only the comparisons with "q value" less than 0.01 and status marked as "OK" in the Cuffdiff output were regarded as showing differential expression.

\section{GO and gene functional analysis of DEGs}

Online Annotation, Visualization and Integrated Discovery (DAVID) Bioinformatics Resources 6.8 was used to gain insight into the biological functions of DEGs, and the enriched Gene Ontology (GO) terms and Kyoto Encyclopedia of Genes and Genomes (KEGG) pathways were both used to analyze DEGs in examined tissues in the background terms and an adjusted $P$-value $<0.05$ was considered significantly overrepresented.

Real-time quantitative RT-PCR (qRT-PCR) experiment

To confirm sequencing results, qRT-PCR was performed to detect the randomly selected DEGs using the same RNA samples for RNA-Seq. Primers were designed via Primer Express 3.0.1 software (Applied Biosystems) and are shown (see online suppl. material) in Suppl. Table S3 (Fb vs Pb). Briefly, $1 \mu$ g of total RNA was reverse-transcribed to cDNA using the SuperScript First Strand cDNA conversion kit (Invitrogen, Carlsbad, CA). qRT-PCR was subsequently carried out in duplicate $25 \mu \mathrm{l}$ reactions using SYBR green master mix (Clontech, cat. No. 638320, TAKARA)[11]. Reactions were run in a 96-well plate using StepOnePlus system (Applied Biosystems). The cycle conditions were as follows: 1 cycle of pre-incubation at $95^{\circ} \mathrm{C}$ for $10 \mathrm{~min}, 40$ cycles of amplification $\left(95^{\circ} \mathrm{C}\right.$ for $30 \mathrm{~s}, 63^{\circ} \mathrm{C}$ for $15 \mathrm{~s}$, and $72^{\circ} \mathrm{C}$ for $\left.20 \mathrm{~s}\right)$. Relative gene expressions of DEGs were calculated using $2^{-\triangle \Delta C t}$ method, and housekeeping gene $G A P D H$ was used as internal control.

\section{Results}

Identification of differentially expressed genes (DEGs) in frontal and parietal bone tissue RNA-Seq produced a total of about 335.66 million raw 100-bp paired-end reads in frontal and parietal bone tissues (Fig. 1A). After quality filtering, about 325.59 million of pair-end clean reads with an average of about 36.18 million for each sample were obtained. Alignment of the sequenced clean reads against the Mus musculus generated about 80.26$85.65 \%$ of uniquely aligned reads by Tophat 2 aligner, and about $96.55-98.70 \%$ reads were aligned in a unique manner, while about 1.3-3.4\% reads were from multiple-mapped reads.

Cufflinks was used to identify the DEGs between frontal bone vs parietal bone. Total 325 DEGs were found in the frontal bone vs parietal bone based on the Fold_Change which was detected by Cuffdiff $(|\mathrm{FC}|>1, p<0.05$, FDR $q<0.05)$. Volcano plots of DEGs between the two tissue compartments, i.e., Fb vs $\mathrm{Pb}$ (Fig. 1B) showed distinct transcriptional profiles. Among the 325 genes, total 118 genes were significantly up-regulated and the left 207 genes were down-regulated (Fig. 1C). Besides, among the 70 high DEGs ( $|\mathrm{FC}|>2, p<0.05$, FDR $q<0.05)$, total 29 genes were found up-regulated in frontal bone vs parietal bone, the left 41 genes were down-regulated in frontal bone tissue vs parietal bone tissues. The top 10 highly expressed genes in frontal bone and parietal bone were listed in Table 1 . The details (Gene ID, Gene name, Fold_Change, p_value, q_value) of all DEGs are shown (see online suppl. material) in Suppl. Table S4 (Fb vs Pb).

In order to understand osteoblast and bone related $\mathrm{DEG}$ in $\mathrm{Fb}$ vs $\mathrm{Pb}$, we further analyzed each DEG based on reported publications (Table 2). We found some interesting fea- 
tures between neural crest derived $\mathrm{Fb}$ and mesoderm derived $\mathrm{Pb}$ at the embryonic stage: 1 ) $\mathrm{Pb}$ produced large amounts of genes expressions related to extracellular matrix, such as Matn1, Matn3, Col9a1, Col9a2, Col2al, Col14a1, Col6a6, Tnn, Acan, Cldn1, Comp, Fndc5 and Smoc1; while $\mathrm{Fb}$ tissue produced low expressions of genes related to matrix. 2) $\mathrm{Fb}$ tissue showed higher levels of some genes related to proliferation, selfrenewal or stem cell niche, such as Ptgfr, which acts as a strong mitogenic and survival agent on osteoblasts [12], but $\mathrm{Pb}$ tissue expressed high levels of genes associated with anti-proliferative properties, such as AATK and SGOL1, which are both apoptosisrelated proteins [13]. 3) $\mathrm{Pb}$ tissue exhibited higher level of osteoblast differentiation by up-regulating genes expressions of Msx2, Twist2, two key transcriptional factor for osteoblast differentiation [14], as well as Ntn1, which plays vital role in osteoblast and osteoclast differentiation [15]. However, Fb tissues
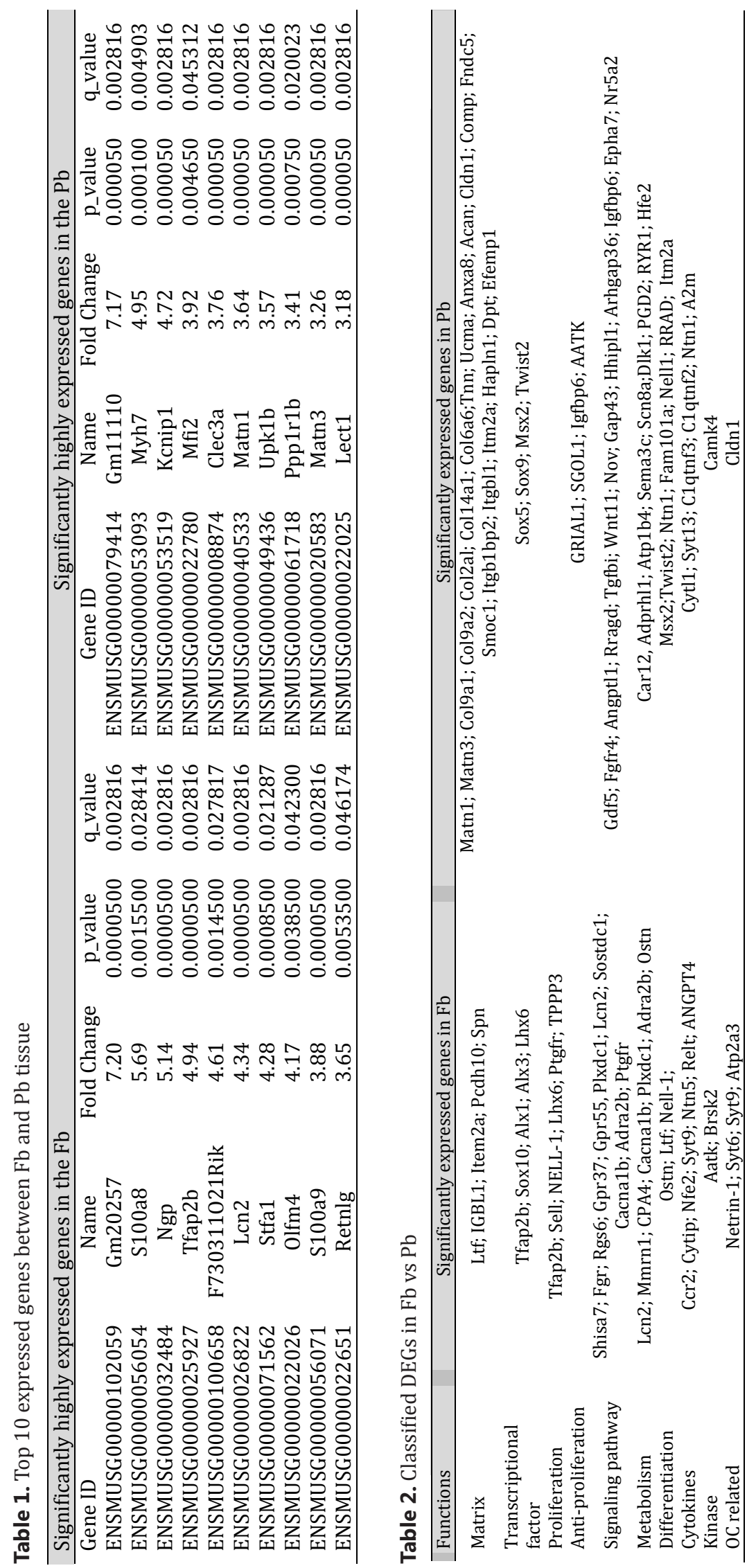


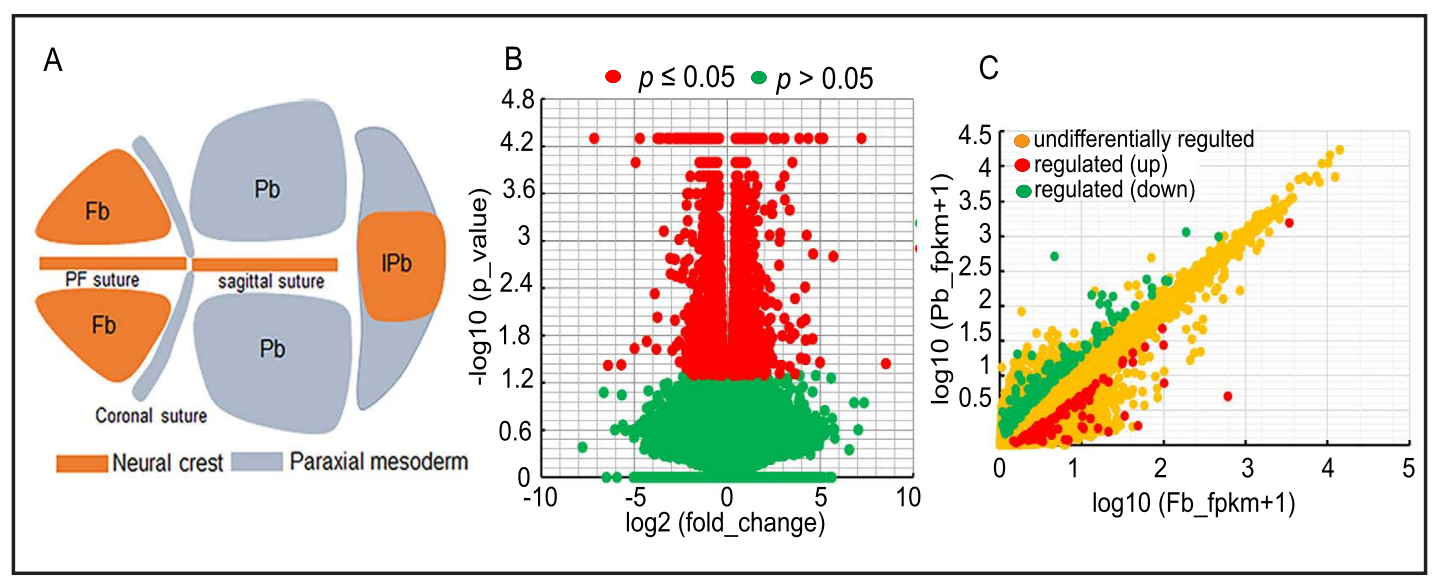

Fig. 1. Volcano plots were used to exhibit DEGs in the Fb vs Pb at E17.5 in mouse skull vault. (A) The diagram of the dual tissue origin of the mouse skull vault, $\mathrm{Fb}$ (frontal bone) is of neural crest origin, and $\mathrm{Pb}$ (parietal bone) is derived from paraxial mesoderm. (B) The DEGs within Fb and Pb. The Y-axis showed the mean expression value of $\log 10$ ( $\mathrm{p}$-value), and the X-axis displayed the log2 (Fold_Change). The red dots showed the significantly expressed genes $(\mathrm{p} \leq 0.05)$ while the green dots indicated the genes with no significant differences. (C) Different populations of DEGs within Fb and Pb. The Y-axis was the value of log10 (fpmk+1) of genes in parietal bone, and X-axis exhibited the value of $\log 10(\mathrm{fpmk}+1)$ of genes in frontal bone. The red dots and green dots represent up- and down-regulated genes between the two groups $(\mathrm{p}<0.05$, FDR q $<0.05)$, respectively, and the yellow dots showed the transcripts with no significant differences ( $p>0.05$, FDR q > 0.05).

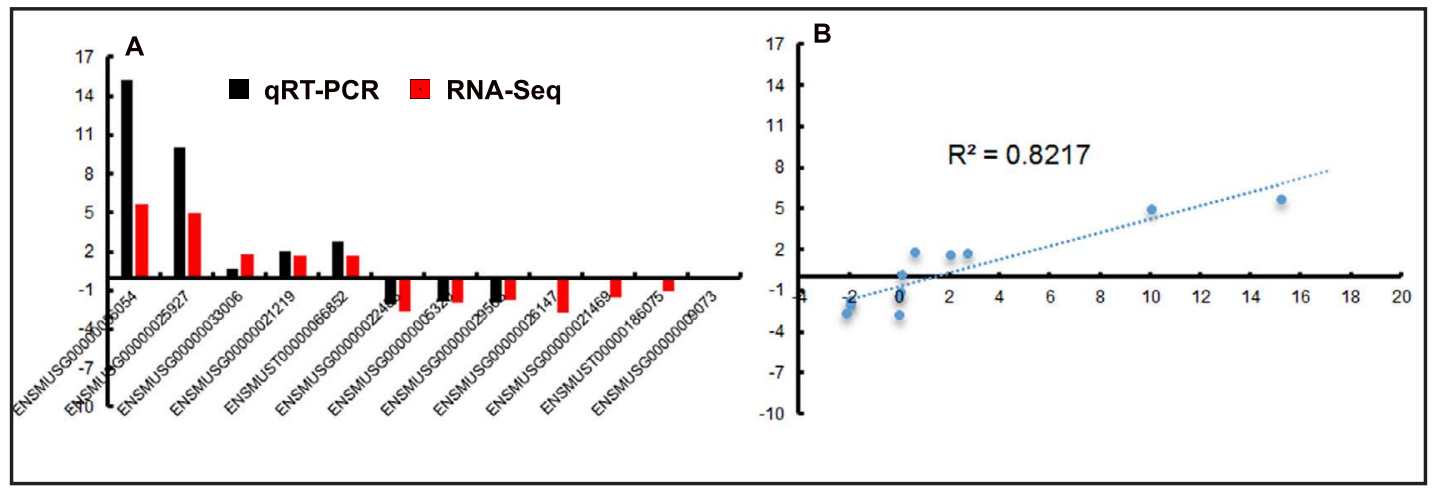

Fig. 2. Validation the data of RNA-seq using qRT-PCR based on selected DEGs. (A) Fold changes of genes between RNA-seq and qRT-PCR. X-axis showed 12 selected genes for qRT-PCR and RNA-seq experiments, and Y-axis represented the log2 (Fold_Change) of the genes from RNA-Seq and qRT-PCR. (B) Regression analysis of the log2 (Fold_Change) between RNA-Seq and qRT-PCR $\left(\mathrm{R}^{2}=0.8217\right)$. The X-and Y-axis exhibited the $\log 2$ (Fold_Change) from qRT-PCR (normalized to GAPDH) and RNA-Seq, respectively.

expressed higher levels of Ostn and Nell1. Ostn is a marker of osteoblast lineage cells [16]. Therefore, osteoblast differentiation program may be regulated differently in frontal bone and parietal bone. 4) Fb tissue displayed higher levels of genes associated with osteoclast activities compared to that in $\mathrm{Pb}$ tissues. 5) Both the tissues expressed some genes to maintain bone metabolism and homeostasis but probably through different "roadmap", such as $\mathrm{Fb}$ produced higher levels of G proteins, Lcn 2 and $\mathrm{Mmm} 1$, while Pb generated higher expressions of zinc finger proteins and Dlk1, PGD2, RYR1 and Hfe2.

\section{Validating RNA-Seq data with qRT-PCR}

To verify the accuracy of fold change detected by RNA-Seq, qRT-PCR analysis was performed for 12 randomly selected DEGs (Sox10, TFAP2, FGFR4, Col2a1, Col9a1, Twist1, Msx2, Foxp2, Nf2, Ostn, Rgs6, S100a8). The comparisons of expression levels of these 12 genes were 
Fig. 3. Functions of DEGs were analyzed using gene ontology term. (A) exhibited the biological process analysis and B was about the molecular function and C represented the cellular components. The top10 significant gene ontology exhibited in each term in $\mathrm{Fb}$ vs $\mathrm{Pb}$. $\mathrm{X}$-axis showed the values of $-\log 10$ ( $p$ value).

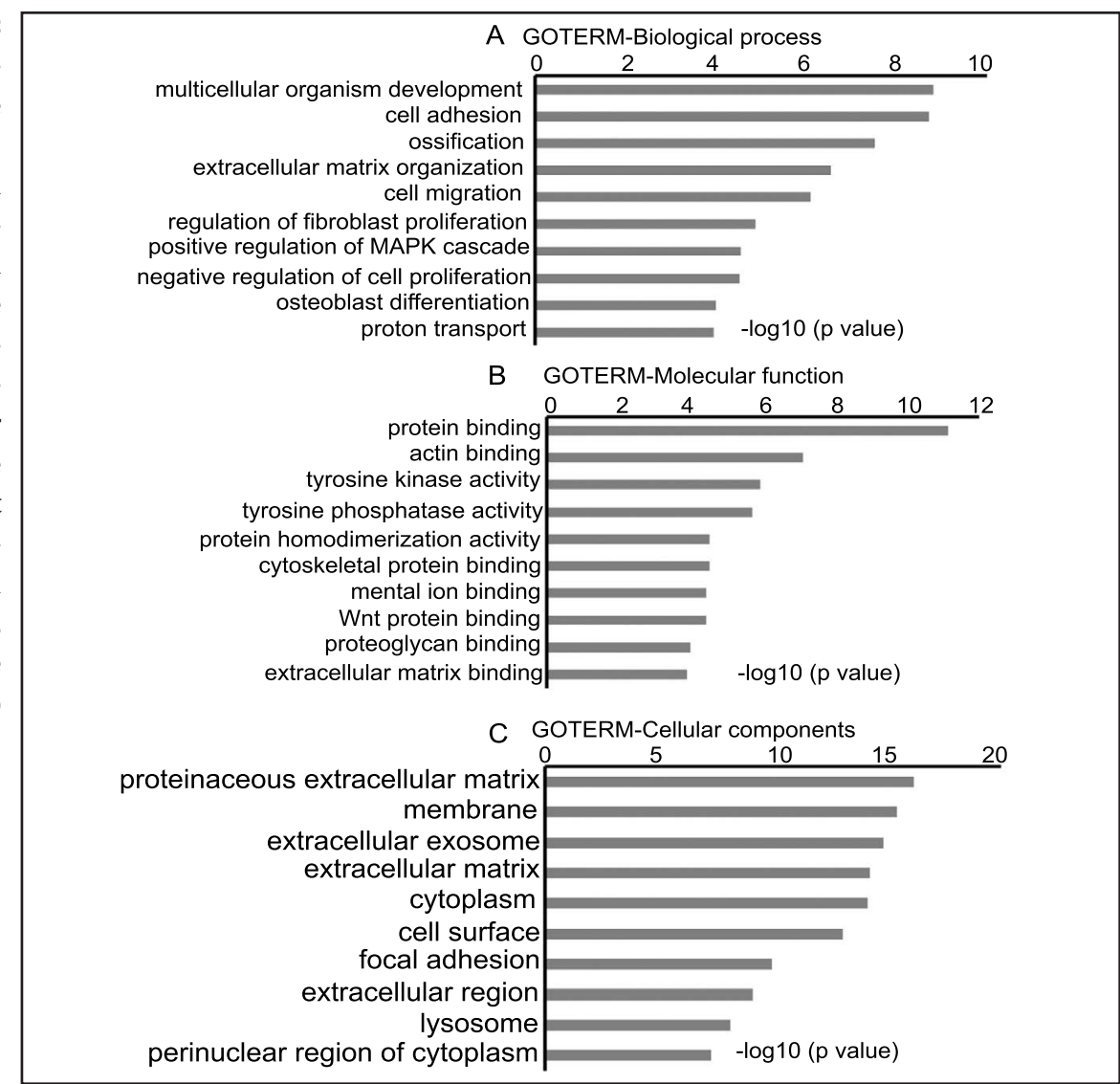

Fig. 4. The potential signaling pathways from clustered DEGs were analyzed using KEGG. Xaxis showed the value of $-\log 10$ ( $p$ value). Identifications of top 11 pathways that DEGs got involved in mouse skull vault were exhibited.

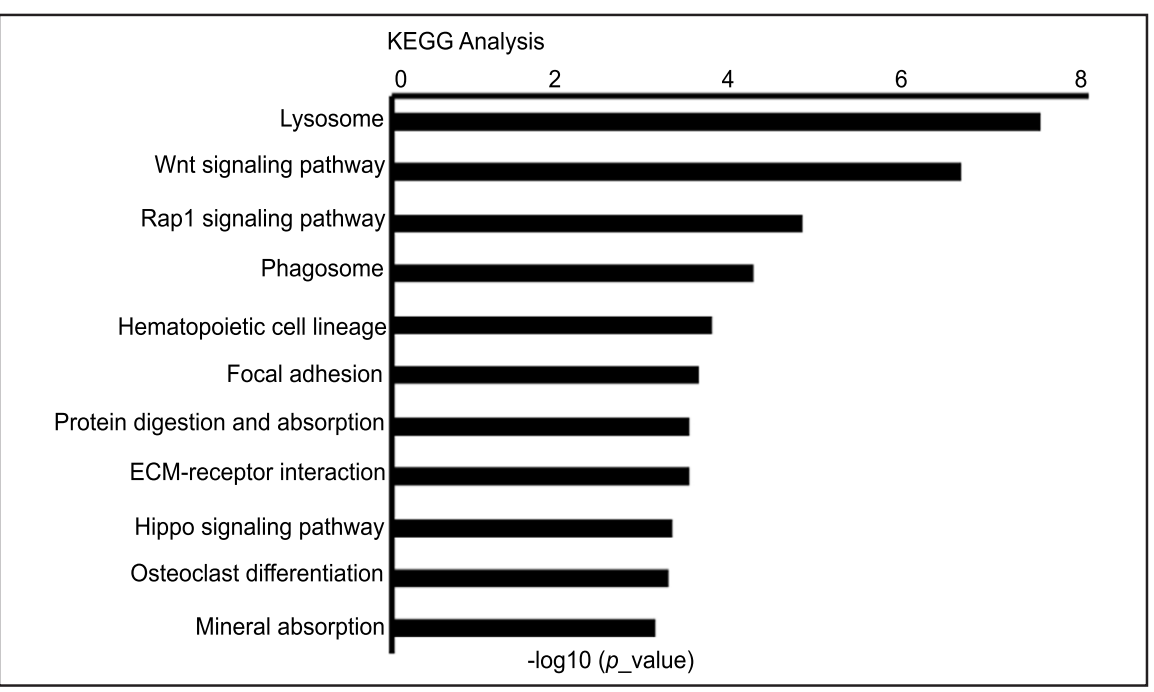

performed between the data from qRT-PCR normalized to GAPDH and those from RNA-seq (Fig. 2A). The comparative results of the fold changes showed that the levels of these DEGs between $\mathrm{Fb}$ vs $\mathrm{Pb}$ tissues were similar and a strong positive correlation with $\mathrm{R}^{2}=0.8217$ in $\mathrm{Fb}$ vs $\mathrm{Pb}$ was produced (Fig. 2B) based on RNA-Seq and qRT-PCR results, suggesting a high reliability of RNA-Seq data in this study.

Gene Ontology enrichment and KEGG pathway analysis

To investigate the functional associations of the DEGs, gene ontology (GO) analysis at the GO database was used for the analysis. We kept each category with an unadjusted threshold 


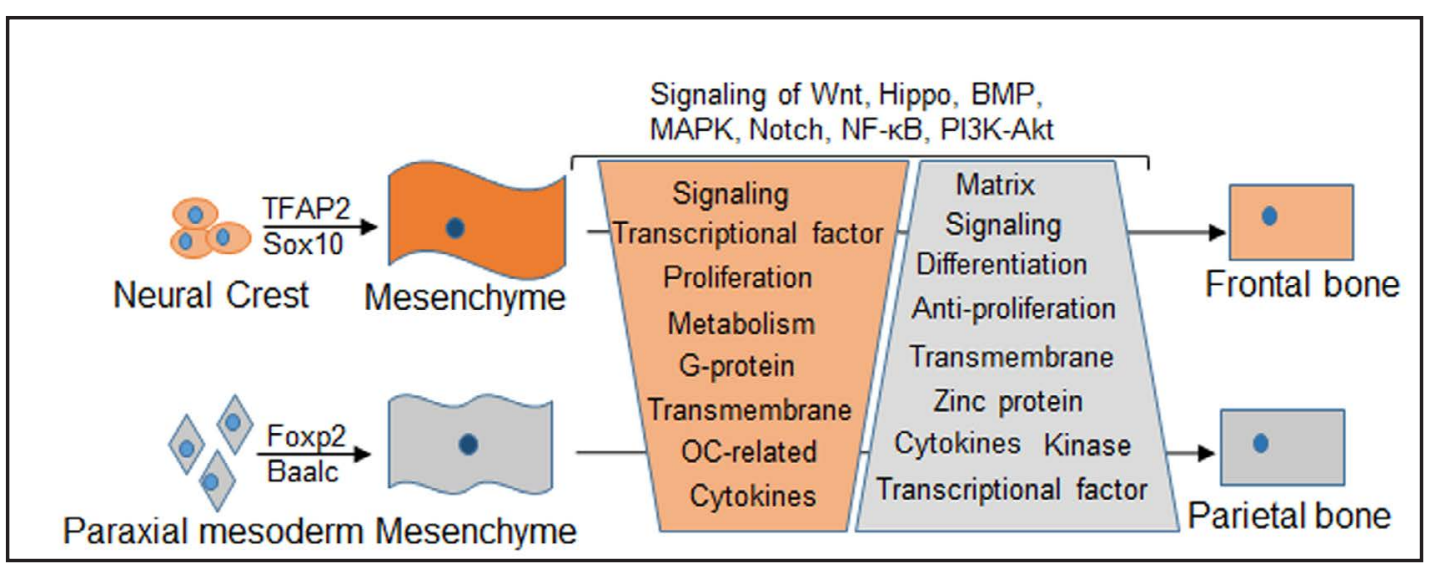

Fig. 5. The proposed model of physiological differences between frontal bone and parietal bone at embryonic stage. Neural crest-derived frontal bone expressed higher levels of TFAP2 and Sox10 while parietal bone showed high expressions of Foxp2 and Baalc in a tissue-specific manner. The frontal bone and parietal bone showed diverse regulations from signaling pathways of Wnt, Hippo, BMP, MAPK, Notch, NF-B and PI3K-Akt which may in turn produce distinct features in proliferation, differentiation, matrix as well as the bone homeostasis.

at $p<0.05$ and at least five DEGs in the background terms were assessed. Multiple pathways and GO terms including biological processes, cellular components and molecular function were significantly enriched for these DEGs. The top 10 details of the significant pathways in the two comparisons were shown in Fig. 3 (Fig. 3) and the detailed analysis was shown (see online suppl. material) in Suppl. Table S5.

DEGs based on KEGG analysis showed that several molecular pathways were involved in frontal bone and parietal bone tissues. In additional to the reported expressions of BMP, FGF, WNT signaling in frontal bone and parietal bone, we found that these differential expressions genes are also clustered into Hippo, MAPK, Notch, NF- $\mathrm{B}$, PI3K-Akt signaling, which will expand the discoveries of these identified signaling upon the regulation within these two bone elements (Fig. 4). The detailed analysis of the pathways can be found (see online suppl. material) in Suppl. Table S6. Based on the differential genes expressions, we proposed the potential regulatory gene network that works on the regulation of frontal bone and parietal bone (Fig. 5). During the neural crest patterning, TFAP2 and Sox10 are highly expressed to maintain the tissue origin of neural crest in frontal bone, while parietal bone highly expressed Foxp2 and Baalc which are regarded as the mesoderm marker to maintain the tissue origin. Under the regulation of the signaling pathways, the frontal bone and parietal bone produced distinct features such as higher levels of genes related to proliferation and bone metabolism and homeostasis in frontal bone, while parietal bone exhibited higher levels of genes associated with matrix, anti-proliferative properties, osteoblast differentiation, suggesting the unrecognized differences between frontal bone and parietal bone.

\section{Discussion}

Frontal bone is derived from neural crest cells driven by Wht1-Cre, while parietal bones are from mesoderm using Mesp1-Cre [1, 2] based on genetic mouse model. Neural crest specifiers, such as Pax3/7, Snail1/2, Sox9/10, Ap2, play essential role for neural crest patterning [17]. We found that neural crest derived frontal bone tissue exhibits higher levels of TFAP2 $b$ and Sox10. TFAP2b is essential for craniofacial development [18]. Sox10 is considered to be one of the earliest neural crest-patterning genes [19, 20]. In humans, TFAP2 is found highly expressed neural crest derived frontal compartment [21], and in chicken, Sox10 is the earliest neural crest-specifying gene [19], suggesting different neural 
crest specifiers may function in species-dependent manner. Parietal bone shows higher expressions of Foxp2 and Baalc. Baalc is regarded as a mesoderm marker [22]. Both Foxf2 and Foxp2 are found highly expressed in mesoderm-derived tissues such as lung [21]. But only Foxf2 is found highly expressed in parietal compartments in human [21]. In short, tissue-specific genes contribute to the tissue origins within skull vault in mouse.

Higher expressions of TFAP2, Lhx6, Nell-1 were found within frontal bone that are associated with cell proliferation. AP2 alpha is required for cell proliferation [23]. AP-2 can determine the mesenchymal fate of cranial neural crest cells [24]. Lhx6 regulates cell proliferation and thereby promotes normal palate development [25]. Nell-1 is a secreted molecule that can induce cranial suture bone growth [26, 27]. However, higher levels of expressions of GRIAL1, SGOL1 and Igfbp6 were found within parietal bone that displayed antiproliferative feature, such as overexpression of GRIAL1 is anti-proliferative [28], and SGOL1 and Igfbp6 are involved in cell apoptosis [29-31]. Foxp2 can increase cell differentiation without affecting cell proliferation and cell survival [32], and transient upregulation of Foxp2 in pre-osteoblast mesenchymal cells regulates a p21-dependent growth arrest checkpoint [33]. Our findings are consistent with the publication that osteoblasts from the neural crestderived frontal bone are less differentiated, grow faster compared to parietal bone-derived osteoblasts [3]. Therefore, tissue-specifically expressed genes influence the physiological states of cells within frontal bone and parietal bone.

Parietal bone exhibits higher levels of extracellular matrix (e.g. Matn1, Matn3, Col9a1, Col9a2, Col2al, Col14a1, Col6a6, Tnn, Ucma, SMOC1, Acan), such as SMOC1 is identified as a putative regulator of osteoblast differentiation [34]. Tenascin is synthesized by osteoblasts [35], and is able to stimulate osteoblastic differentiation through working with WNT signaling and BMP signaling [36]. Besides, parietal bone expressed higher levels of Msx2, Twist2, which are well-known transcriptional factor for osteoblast differentiation and bone formation $[14,37]$. The higher levels of these genes expressions may account for osteoblast differentiation within parietal bone. Besides, some unrecognized signaling pathways may regulate dual tissue origins in skull vault, such as Hippo, MAPK, Notch, NF- $\kappa B$, PI3K-Akt signaling, as well as the genes related to bone homeostasis, such as LCN2, acting as a bonederived hormone with metabolic regulatory effects $[38,39]$ is highly expressed in frontal bone. How these genes and signaling pathways converge together to orchestrate bone formation and homeostasis are very interesting.

Taken together, our data shows that differentially expressed genes contributes to the tissue origins and physiological states within the two bones in the mouse skull vault, which expand the novel insights into the potential gene regulatory network in regulating the frontal bone and parietal bone development. Skull vault with dual tissue origins is a valuable model to understand cellular and genetic mechanism about the regional differences, which is beneficial to not only the bone biology but also the regenerative medicine in clinic.

\section{Acknowledgements}

The work is supported by grants by National Natural Science Foundation of China (No. 81400489) and Science and Technology Planning Project of Jiaxing (2017AY33056). Thanks to Dr. Shahrnaz Kemal (Northwestern University) for her critical review of our manuscript. We apologize to the many researchers whose work could not be cited due to space limitations.

\section{Disclosure Statement}

The Authors declare no Disclosure Statement. 


\section{Cellular Physiology Cell Physiol Biochem 2017;43:2525-2534 \begin{tabular}{ll|l} 
and Biochemistry Published online: November 02, 2017 & $\begin{array}{l}\text { (c) } 2017 \text { The Author(s). Published by S. Karger AG, Basel } \\
\text { www.karger.com/cpb }\end{array}$
\end{tabular}}

Hu et al.: Dual Tissue Origins Within Skull Vault

\section{References}

1 Kuratani S: Cephalic neural crest cells and the evolution of craniofacial structures in vertebrates: morphological and embryological significance of the premandibular-mandibular boundary. Zoology (Jena) 2005;108:13-25.

2 Jiang X, Iseki S, Maxson RE, Sucov HM, Morriss-Kay GM: Tissue origins and interactions in the mammalian skull vault. Dev Biol 2002;241:106-116.

-3 Xu Y, Malladi P, Zhou D, Longaker MT: Molecular and cellular characterization of mouse calvarial osteoblasts derived from neural crest and paraxial mesoderm. Plast Reconstr Surg 2007;120:1783-1795.

-4 Quarto N, Behr B, Li S, Longaker MT: Differential FGF ligands and FGF receptors expression pattern in frontal and parietal calvarial bones. Cells Tissues Organs 2009;190:158-169.

-5 Quarto N, Wan DC, Kwan MD, Panetta NJ, Li S, Longaker MT: Origin matters: differences in embryonic tissue origin and Wnt signaling determine the osteogenic potential and healing capacity of frontal and parietal calvarial bones. J Bone Miner Res 2010;25:1680-1694.

6 Li S, Quarto N, Senarath-Yapa K, Grey N, Bai X, Longaker MT: Enhanced Activation of Canonical Wnt Signaling Confers Mesoderm-Derived Parietal Bone with Similar Osteogenic and Skeletal Healing Capacity to Neural Crest-Derived Frontal Bone. PLoS One 2015;10:e0138059.

7 Senarath-Yapa K, Li S, Meyer NP, Longaker MT, Quarto N: Integration of multiple signaling pathways determines differences in the osteogenic potential and tissue regeneration of neural crest-derived and mesoderm-derived calvarial bones. Int J Mol Sci 2013;14:5978-5997.

8 Li S, Quarto N, Longaker MT: Activation of FGF signaling mediates proliferative and osteogenic differences between neural crest derived frontal and mesoderm parietal derived bone. PLoS One 2010;5:e14033.

-9 Pollier J, Rombauts S, Goossens A: Analysis of RNA-Seq data with TopHat and Cufflinks for genome-wide expression analysis of jasmonate-treated plants and plant cultures. Methods Mol Biol 2013;1011:305-315.

10 Trapnell C, Roberts A, Goff L, Pertea G, Kim D, Kelley DR, Pimentel H, Salzberg SL, Rinn JL, Pachter L: Differential gene and transcript expression analysis of RNA-seq experiments with TopHat and Cufflinks. Nat Protoc 2012;7:562-578.

11 Shen X, Hu B, Xu G, Chen F, Ma R, Zhang N, Liu J, Ma X, Zhu J, Wu Y, Shen R: Activation of Nrf2/HO-1 Pathway by Glycogen Synthase Kinase-3beta Inhibition Attenuates Renal Ischemia/Reperfusion Injury in Diabetic Rats. Kidney Blood Press Res 2017;42:369-378.

12 Agas D, Marchetti L, Hurley MM, Sabbieti MG: Prostaglandin F2alpha: a bone remodeling mediator. J Cell Physiol 2013;228:25-29.

13 Zhu RX, Song CH, Yang JS, Yi QT, Li BJ, Liu SH: Downregulation of AATK mediates microRNA-558-induced resistance of A549 cells to radiotherapy. Mol Med Rep 2016;14:2846-2852.

14 Ishii M, Merrill AE, Chan YS, Gitelman I, Rice DP, Sucov HM, Maxson RE, Jr:: Msx2 and Twist cooperatively control the development of the neural crest-derived skeletogenic mesenchyme of the murine skull vault. Development 2003;130:6131-6142.

-15 Sato T, Kokabu S, Enoki Y, Hayashi N, Matsumoto M, Nakahira M, Sugasawa M, Yoda T: Functional Roles of Netrin-1 in Osteoblast Differentiation. In vivo 2017;31:321-328.

16 Bord S, Ireland DC, Moffatt P, Thomas GP, Compston JE: Characterization of osteocrin expression in human bone. J Histochem Cytochem 2005;53:1181-1187.

17 Stuhlmiller TJ, Garcia-Castro MI: Current perspectives of the signaling pathways directing neural crest induction. Cell Mol Life Sci 2012;69:3715-3737.

18 Schorle H, Meier P, Buchert M, Jaenisch R, Mitchell PJ: Transcription factor AP-2 essential for cranial closure and craniofacial development. Nature 1996;381:235-238.

19 Betancur P, Bronner-Fraser M, Sauka-Spengler T: Genomic code for Sox10 activation reveals a key regulatory enhancer for cranial neural crest. Proc Natl Acad Sci U S A 2010;107:3570-3575.

20 Simoes-Costa M, Bronner ME: Reprogramming of avian neural crest axial identity and cell fate. Science 2016;352:1570-1573.

21 Homayounfar N, Park SS, Afsharinejad Z, Bammler TK, MacDonald JW, Farin FM, Mecham BH, Cunningham ML: Transcriptional analysis of human cranial compartments with different embryonic origins. Arch Oral Biol 2015;60:1450-1460.

-22 Satoskar AA, Tanner SM, Weinstein M, Qualman SJ, de la Chapelle A: Baalc, a marker of mesoderm and muscle. Gene Expr Patterns 2005;5:463-473. 


\section{Cellular Physiology Cell Physiol Biochem 2017;43:2525-2534 \begin{tabular}{l|l|l} 
and Biochemistry & $\begin{array}{l}\text { DOI: 10.1159/000484496 } \\
\text { Published online: November 02, 2017 }\end{array}$ & $\begin{array}{l}\text { C) } 2017 \text { The Author(s). Published by S. Karger AG, Basel } \\
\text { www.karger.com/cpb }\end{array}$
\end{tabular}}

23 Pfisterer P, Ehlermann J, Hegen M, Schorle H: A subtractive gene expression screen suggests a role of transcription factor AP-2 alpha in control of proliferation and differentiation. J Biol Chem 2002;277:66376644.

-24 Minarcik JC, Golden JA: AP-2 and HNK-1 define distinct populations of cranial neural crest cells. Orthod Craniofac Res 2003;6:210-219.

25 Cesario JM, Landin Malt A, Deacon LJ, Sandberg M, Vogt D, Tang Z, Zhao Y, Brown S, Rubenstein JL, Jeong J: Lhx6 and Lhx8 promote palate development through negative regulation of a cell cycle inhibitor gene, p57Kip2. Hum Mol Genet 2015;24:5024-5039.

-26 Pang S, Shen J, Liu Y, Chen F, Zheng Z, James AW, Hsu CY, Zhang H, Lee KS, Wang C, Li C, Chen X, Jia H, Zhang $\mathrm{X}$, Soo C, Ting K: Proliferation and osteogenic differentiation of mesenchymal stem cells induced by a short isoform of NELL-1. Stem Cells 2015;33:904-915.

27 Cowan CM, Cheng S, Ting K, Soo C, Walder B, Wu B, Kuroda S, Zhang X: Nell-1 induced bone formation within the distracted intermaxillary suture. Bone 2006;38:48-58.

28 Bernardini G, Laschi M, Serchi T, Spreafico A, Botta M, Schenone S, Arena S, Geminiani M, Scaloni A, Collodel G, Orlandini M, Niccolai N, Santucci A: Proteomics and phosphoproteomics provide insights into the mechanism of action of a novel pyrazolo [3, 4-d]pyrimidine Src inhibitor in human osteosarcoma. Mol Biosyst 2014;10:1305-1312.

29 Bei Y, Huang Q, Shen J, Shi J, Shen C, Xu P, Chang H, Xia X, Xu L, Ji B, Chen J: IGFBP6 Regulates Cell Apoptosis and Migration in Glioma. Cell Mol Neurobiol 2017;37:889-898.

30 Wang S, Liu Y, Wu C, Zhao W, Zhang J, Bao G, Xu G, Sun Y, Chen J, Cui Z: The Expression of IGFBP6 after Spinal Cord Injury: Implications for Neuronal Apoptosis. Neurochem Res 2017;42:455-467.

-31 Matsuura S, Kahyo T, Shinmura K, Iwaizumi M, Yamada H, Funai K, Kobayashi J, Tanahashi M, Niwa H, Ogawa H, Takahashi T, Inui N, Suda T, Chida K, Watanabe Y, Sugimura H: SGOL1 variant B induces abnormal mitosis and resistance to taxane in non-small cell lung cancers. Sci Rep 2013;3:3012.

-32 Chiu YC, Li MY, Liu YH, Ding JY, Yu JY, Wang TW: Foxp2 regulates neuronal differentiation and neuronal subtype specification. Dev Neurobiol 2014;74:723-738.

-33 Gascoyne DM, Spearman H, Lyne L, Puliyadi R, Perez-Alcantara M, Coulton L, Fisher SE, Croucher PI, Banham AH: The Forkhead Transcription Factor FOXP2 Is Required for Regulation of p21WAF1/CIP1 in 143B Osteosarcoma Cell Growth Arrest. PLoS One 2015;10:e0128513.

34 Choi YA, Lim J, Kim KM, Acharya B, Cho JY, Bae YC, Shin HI, Kim SY, Park EK: Secretome analysis of human BMSCs and identification of SMOC1 as an important ECM protein in osteoblast differentiation. J Proteome Res 2010;9:2946-2956.

35 Mackie EJ, Tucker RP: Tenascin in bone morphogenesis: expression by osteoblasts and cell type-specific expression of splice variants. J Cell Sci 1992;103 ( Pt 3):765-771.

-36 Chen G, Deng C, Li YP: TGF-beta and BMP signaling in osteoblast differentiation and bone formation. Int J Biol Sci 2012;8:272-288.

-37 Nakamura T, Toita H, Yoshimoto A, Nishimura D, Takagi T, Ogawa T, Takeya T, Ishida-Kitagawa N: Potential involvement of Twist 2 and Erk in the regulation of osteoblastogenesis by HB-EGF-EGFR signaling. Cell Struct Funct 2010;35:53-61.

-38 Mosialou I, Shikhel S, Liu JM, Maurizi A, Luo N, He Z, Huang Y, Zong H, Friedman RA, Barasch J, Lanzano P, Deng L, Leibel RL, Rubin M, Nicholas T, Chung W, Zeltser LM, Williams KW, Pessin JE, Kousteni S: MC4Rdependent suppression of appetite by bone-derived lipocalin 2. Nature 2017;543:385-390.

-39 Greenhill C: Bone: Osteoblast-derived lipocalin 2 suppresses appetite. Nat Rev Endocrinol 2017;13:250. 